\title{
The Use of Long Acting Reversible Contraceptives and the Relationship between Discontinuation Rates due to Menopause and to Female and Male Sterilizations
}

\section{Uso de contraceptivos reversíveis de longa duração e a relação entre taxas de descontinuidade devido à menopausa e à esterilização de homens e mulheres}

Jessica Mayra Ferreira ${ }^{1}$ Ilza Monteiro ${ }^{1}$ Sara Castro $^{2}$ Marina Villarroel $^{2}$

Carolina Silveira $^{1}$ Luis Bahamondes ${ }^{1}$

${ }^{1}$ Department of Obstetrics and Gynecology, Faculdade de Ciências Médicas, Universidade Estadual de Campinas - Unicamp, Campinas, SP, Brazil

2 Family Planning Clinic, Women's Hospital (CAISM), Faculdade de Ciências Médicas, Universidade Estadual de Campinas - Unicamp, Campinas, SP, Brazil

Rev Bras Ginecol Obstet 2016;38:210-217.

\begin{abstract}
Address for correspondence Luis Bahamondes, PhD, Department of Obstetrics and Gynecology, Faculdade de Ciências Médicas, Universidade Estadual de Campinas - Unicamp, Caixa Postal 6181, 13084 971 Campinas, SP, Brazil (e-mail: bahamond@caism.unicamp.br).
\end{abstract}

\begin{abstract}
Introduction Women require effective contraception until they reach menopause. The long acting reversible contraceptives (LARC) and the depot-medroxyprogesterone acetate (DMPA, Depo-Provera ${ }^{\circledR}$, Pfizer, Puurs, Belgium) are great options and can replace possible sterilizations.

Purpose To assess the relationship between the use of LARCs and DMPA and terminations ascribed to menopause and sterilizations in a Brazilian clinic.

Methods We reviewed the records of women between 12 and 50 years of age attending the clinic that chose to use a LARC method or DMPA. Cumulative termination rates due to sterilization or because the woman had reached menopause were computed using single decrement life-table analysis over 32 years. We also examined all records of surgical sterilization at our hospital between the years 1980-2012.

Keywords

- long acting reversible contraceptives

- sterilization

- menopause

- copper IUD

- LNG-IUS

Results Three hundred thirty-two women had continuously used the same contraceptive until menopause, and 555 women had discontinued the method because they or their partners underwent sterilization. From year 20 to year 30 of use, levonorgestrel intrauterine-releasing system (LNG-IUS - Mirena ${ }^{\circledR}$, Bayer Oy, Turku, Finland; available since 1980), copper intrauterine device (IUD - available since 1980) and DMPA users showed a trend of cumulative higher discontinuation rates due to menopause when compared with the discontinuation rates due to sterilization. Over the study period, a steep decline in the use of sterilization occurred.
\end{abstract}

received

January 1, 2016

accepted

March 16, 2016

published online

May 17, 2016
Copyright $\odot 2016$ by Thieme Publicações License terms Ltda, Rio de Janeiro, Brazil
DOI http://dx.doi.org/

$10.1055 / \mathrm{s}-0036-1583758$ ISSN 0100-7203.
(®) $\Theta \circledast$ 


\section{Resumo}

\author{
Palavras-chave \\ - contraceptivos \\ reversíveis de longa \\ duração \\ - esterilização \\ - menopausa \\ - Diu de cobre \\ - SIU-LNG
}

Conclusion Over the past 15 years of research we have observed a trend: women usually preferred to continue using LARC methods or DMPA until menopause rather than decide for sterilization, be it their own, or their partners'. The annual number of sterilizations dropped in the same period. The use of LARC methods and DMPA until menopause is an important option to avoid sterilization, which requires a surgical procedure with potential complications.

Introdução Mulheres necessitam de contracepção até atingirem a menopausa. Os contraceptivos reversíveis de longa duração e o acetato de medroxiprogesterona de depósito (AMPD) são ótimas opções para substituir possíveis esterilizações.

Objetivo Avaliar a relação entre o uso de contraceptivos reversíveis de longa duração (LARCs) e AMPD com terminações atribuídas à menopausa e a esterilizações em uma clínica brasileira.

Métodos Revisamos os registros de mulheres entre 12 e 50 anos de idade atendidas em clínica e que escolheram usar LARC ou AMPD. Índices de terminação acumulada devido à esterilização ou à menopausa foram computados usando análise de tabela de vida durante 32 anos. Também examinamos todos os registros de cirurgias de esterilização em nosso hospital no período de 1980 a 2012.

Resultados Trezentas e trinta e duas mulheres usaram continuamente o mesmo contraceptivo até a menopausa, e 555 mulheres não deram continuidade ao método pelo fato de elas ou seus parceiros terem se submetido à esterilização. De 20 a 30 anos de uso, usuários de sistema intrauterino de levonorgestrel, dispositivo intrauterino de cobre e AMPD apresentaram tendência de maiores índices de descontinuidade devido à menopausa quando comparados a índices de descontinuidade devido à esterilização. No período de estudo, ocorreu um declínio acentuado no uso de esterilização.

Conclusão Nos últimos 15 anos do estudo, foi observada uma tendência na qual mulheres optaram mais por continuar usando LARC ou AMPD até a menopausa do que pela esterilização própria ou de seus parceiros. O número anual de esterilizações caiu no mesmo período. O uso de LARC e AMPD até a menopausa é uma opção importante para evitar a esterilização, que exige um procedimento cirúrgico com potenciais complicações.

\section{Introduction}

Unintended pregnancies represent a major public health issue. In developed countries, more than $40 \%$ of pregnancies occurring each year are unintended. ${ }^{1}$ Despite the decline in fertility with age, women require effective contraception until they reach menopause. ${ }^{2}$ Worldwide, $61 \%$ of women with ages from 15 to 49 use some kind of contraception to avoid pregnancy; however, a considerable proportion of unintended pregnancies continues to occur due to incorrect use or premature discontinuation of contraceptive methods. ${ }^{3}$

For women who find it difficult to use a contraceptive that requires daily or periodic attention, long-acting reversible contraceptives (LARCs; the copper intrauterine device [CuIUD], the levonorgestrel-releasing intrauterine system [LNGIUS], levonorgestrel- [LNG - Norplant ${ }^{\circledR}$, Bayer Oy, Turku, Finland; available since between 1985 and August 2001] and etonogestrel [ENG - Implanon ${ }^{\circledR}$, Merck, Oss, Holland available since 2003] - releasing subdermal implants) and DMPA represent a possible option due to their very low failure rates, which are similar to those found with female sterilization. ${ }^{4}$
Many women need contraception during 28 to 30 years of their lives and after the birth of their last child they still need contraception for 15 years or more. ${ }^{5}$ Despite the availability of many reversible contraceptives, female and male sterilization remains a popular method worldwide. Between 2003 and 2004 in the United Kingdom (UK), around $25 \%$ of couples opted for female or male sterilization, ${ }^{6}$ while $37 \%$ of women in the United States (US) chose sterilization. ${ }^{7}$ In Brazil, around $29 \%$ of women have opted for sterilization. ${ }^{8}$

Female sterilization is associated with several risks, including subsequent regret, unplanned and ectopic pregnancy, bowel and bladder injuries, complications related to anesthesia, pain following the procedure and dyspareunia. ${ }^{9}$ Furthermore, life table analysis of 10-year cumulative failure rates of sterilization methods range from 36.5 per 1,000 procedures for clip sterilization to 7.5 per 1,000 procedures both for unipolar coagulation and for postpartum partial salpingectomy, with ectopic pregnancy occurring in 7.3 cases per 1,000 procedures. With respect to vasectomy, 
postoperative hematoma, pain, infection and granuloma are the most common complications. ${ }^{10}$

Due to the safety of LARC methods and DMPA, these contraceptives are excellent options for women who have completed their families and need contraception for many more years until menopause. ${ }^{1,4,8}$ There is scarce information on the uninterrupted long-term use of LARC methods or DMPA until menopause and its relationship to the number of female or male sterilizations. Consequently, the aim of this study was to investigate this relationship in more detail and to contrast the characteristics of the women who switch from copper IUD, LNG-IUS, implants and DMPA to permanent contraception with those of the women who continued to use these reversible methods until menopause at a Brazilian university-based clinic.

\section{Methods}

This was a study performed at the Family Planning Clinic, Department of Obstetrics and Gynecology, Faculdade de Ciências Médicas, Universidade Estadual de Campinas (Unicamp), Campinas, São Paulo, Brazil. The clinic was established over 30 years ago. The Ethical Committee approved the protocol. Informed consent was waived because the study consisted of reviewing medical records and the data were retrieved without identifying the women. Details of different aspects of this study have been published previously. ${ }^{8}$

\section{Population and Participants}

Women of 12 to 50 years of age attending the clinic were able to freely choose whether they wanted to use copper IUD, LNG-IUS, LNG-releasing implant, ENG-releasing implant, DMPA or other contraceptive methods. For those women who chose copper IUD, the device available from the beginning of the study up to April 1988 was the TCu200B. After that date and up to 2001, the device available was the TCu380A (ParaGard®, Ortho Pharmaceutical, Don Mills, Ontario, Canada). From 2001 onwards, the Optima ${ }^{\circledR}$ TCu380AIUD (which is identical in shape and copper surface to the TCu380A manufactured in the US) (Injeflex, São Paulo, Brazil) was the device available.

Taking into consideration the 50,004 medical charts available at the clinic of women who had consulted for the first time between January 2nd, 1980 and December 31st, 2012 , we were able to obtain 16,115 medical charts of the women who came to the clinic for a follow-up for at least one year. We identified 20,821 segment of use of copper IUD, LNG-IUS, implants and DMPA users (women who had these contraceptives as first option or those who were using other method and switched to one of the studied methods). Women who received LNG-IUS exclusively for therapeutic purposes were excluded from the study. The women who adopted one of the methods and later switched to sterilization or reached menopause before the end of the first year of follow-up were excluded from the analysis.

For data analysis, the number of years spent using the method was considered continuous if a copper IUD, LNG-IUS or implant user replaced the device with another on the same day in which the previous device was removed, at the end of its contraceptive life span. A previous publication from our clinic $^{8}$ reported on continuation and pregnancy rates. This report presents data from the same cohorts regarding terminations when women reached menopause or when the women or their partners were sterilized. To evaluate use until menopause, the termination date was considered as the last day of menstruation or, in the case of amenorrheic women, the day of the second follicle-stimulating hormone (FSH) measurement (the latter measured 90 days after the former) with values $>40 \mathrm{mIU} / \mathrm{mL}$.

Cumulative survival rates (for each method) and termination rates consequent to female or male sterilization or because the woman had reached menopause were evaluated using single decrement life-table analysis (with annual intervals). Other terminations and failures to follow-up were treated as censored cases. The Wilcoxon-Gehan test was used to assess statistical significance of the differences between rates.

Sociodemographic data of women who terminated for these two reasons are presented as means \pm standard error of the mean (SEM) or as percentage distributions for categorical variables. Life table data are presented in 5-year intervals up to a total of 30 years of use; however, the total evaluation period covered 32 years. Two sets of cumulative termination rates attributed to menopause or sterilization of each contraceptive are presented as rates per 100 with their standard errors (SEs). The SPSS statistical software program, version 20 (Chicago, USA, 2012), was used. Significance was established at $p<0.05$.

\section{Results}

A chart review showed that 332 women had used a LARC method or DMPA until menopause, and that 555 women had discontinued because they or their partners had opted for surgical sterilization at our hospital or returned to our clinic for follow-up after a surgical procedure performed elsewhere. - Table 1 lists the women's principal sociodemographic characteristics. The mean age \pm SEM of the women at admission to the study was $37.0 \pm 0.36$ years for women who used the method until menopause, and $30.3 \pm 0.23$ years $(p<0.001)$ for those who had discontinued due to sterilization. The pattern of significantly younger age at admission for the women, or their partners, whose fertility ended with sterilization was observed in each decade. Additionally, most of the women who underwent sterilization had their first consultation at our clinic at the age of 34 or less.

At admission, among those who used the method until menopause, most reported between 1-4 years of schooling (59.5\%), whereas the largest group (46.6\%) of women who discontinued due to sterilization reported between 5-8 years of schooling.

- Table 2 shows the cumulative termination rates resulting from sterilization or from menopause and the contraceptive method used uninterruptedly since the woman's first visit to the clinic. The data are displayed in 5-year segments, 
Table 1 Baseline characteristics of the women using LARC contraceptives and DMPA until menopause or until undergoing sterilization

\begin{tabular}{|c|c|c|c|}
\hline Characteristics & $\begin{array}{l}\text { Women who continued } \\
\text { reversible contraceptive use } \\
\text { until menopause }(n=332)\end{array}$ & $\begin{array}{l}\text { Women who opted for } \\
\text { surgical contraception } \\
(n=555)\end{array}$ & $p$-value \\
\hline Age at admission (years) ${ }^{a}$ & $\begin{array}{l}\text { Mean } \pm \text { SEM (range) } n \\
37.0 \pm 0.36(20-53)\end{array}$ & $\begin{array}{l}\text { Mean } \pm \text { SEM (range) } n \\
30.3 \pm 0.23(16-46)\end{array}$ & $\begin{array}{l}p \text { - value } \\
<0.001^{*}\end{array}$ \\
\hline Decade of $1980-1989^{b}$ & $32.2 \pm 5.4(20-46) 123$ & $26.3 \pm 4.2(18-35) 50$ & \\
\hline $\begin{array}{l}\text { Decade of } 1990-1999^{b} \\
\text { Decade of } 2000-2009^{a} \\
\text { Decade of } 2010-2012^{b}\end{array}$ & $\begin{array}{l}38.5 \pm 5.2(20-51) 156 \\
43.1 \pm 4.9(27-53) 49 \\
40.1 \pm 8.7(30-51) 4\end{array}$ & $\begin{array}{l}29.4 \pm 5.1(16-45) 244 \\
31.9 \pm 5.4(20-46) 247 \\
31.0 \pm 4.6(26-38) 14\end{array}$ & \\
\hline Women over 30 years old at admission (\%) & 85.2 & 53.5 & $<0.001$ \\
\hline Women over 35 years old at admission (\%) & 62.6 & 22.0 & $<0.001$ \\
\hline Number of pregnancies & $\mathrm{n}(\%)$ & $\mathrm{n}(\%)$ & $0.073^{\#}$ \\
\hline $0-2$ & $156(47.0)$ & $219(39.4)$ & \\
\hline $3-4$ & $129(38.8)$ & $234(42.2)$ & \\
\hline$\geq 5$ & $47(14.2)$ & $102(18.4)$ & \\
\hline Years of schooling & & & $<0.001^{\#}$ \\
\hline Illiterate & $22(6.6)$ & $24(4.3)$ & \\
\hline $1-4$ & $193(58.1)$ & $170(30.6)$ & \\
\hline $5-8$ & $77(23.2)$ & $258(46.5)$ & \\
\hline $9-12$ & $29(8.7)$ & $91(16.4)$ & \\
\hline$>12$ & $11(3.4)$ & $12(2.2)$ & \\
\hline
\end{tabular}

Abbreviation: DMPA, depot-medroxyprogesterone acetate; LARCs, long acting reversible contraceptives; SEM, standard error of the mean. Notes: ${ }^{a}$ Mean \pm SEM; ${ }^{\text {bMean }} \pm$ standard deviation; *t-test; " Pearson Chi-square.

Table 2 Cumulative discontinuation rates (with SEs) of LARC contraceptives and DMPA due to menopause or to male or female surgical sterilization for each 5-year segment

\begin{tabular}{|c|c|c|c|c|}
\hline \multirow{2}{*}{$\begin{array}{l}\text { Reason/ } \\
\text { Periods of use (years) }\end{array}$} & \multicolumn{4}{|l|}{ Contraceptive method } \\
\hline & Implant & Copper IUD & LNG-IUS & DMPA \\
\hline \multicolumn{5}{|l|}{ Menopause } \\
\hline 5 & $0.0(<$ glyph name ="sbnd" $/>)$ & $0.2(<0.1)$ & $0.7(0.3)$ & $1.8(0.4)$ \\
\hline 10 & 0.0 (<glyph name="sbnd" />) & $1.5(0.2)$ & $7.6(2.4)$ & $9.6(1.5)$ \\
\hline 15 & $3.1(3.1)$ & $6.6(0.7)$ & $13.7(3.8)$ & $25.3(3.5)$ \\
\hline 20 & $12.1(6.7)$ & $17.7(1.7)$ & $31.7(12.2)$ & $57.3(8.4)$ \\
\hline 25 & $12.1(6.7)$ & $43.7(4.2)$ & $31.7(12.2)$ & 69.5 (11.9) \\
\hline \multicolumn{5}{|c|}{ Female or male sterilization } \\
\hline 5 & $2.5(1.2)$ & $0.5(0.1)$ & $1.8(0.5)$ & $8.6(0.7)$ \\
\hline 10 & $2.5(1.2)$ & $3.7(0.3)$ & $4.2(1.5)$ & $12.4(1.1)$ \\
\hline 15 & $2.5(1.2)$ & $6.8(0.5)$ & $6.1(2.4)$ & $15.6(1.8)$ \\
\hline 20 & $20.2(9.3)$ & $10.0(1.0)$ & $6.1(2.4)$ & $17.5(2.6)$ \\
\hline 25 & $20.2(9.3)$ & $11.3(1.6)$ & $6.1(2.4)$ & $17.5(2.6)$ \\
\hline
\end{tabular}

Abbreviations: Copper IUD, copper intrauterine device; DMPA, depot-medroxyprogesterone acetate; LARCs, long acting reversible contraceptives; LNG-IUS, levonorgestrel intrauterine-releasing system. 

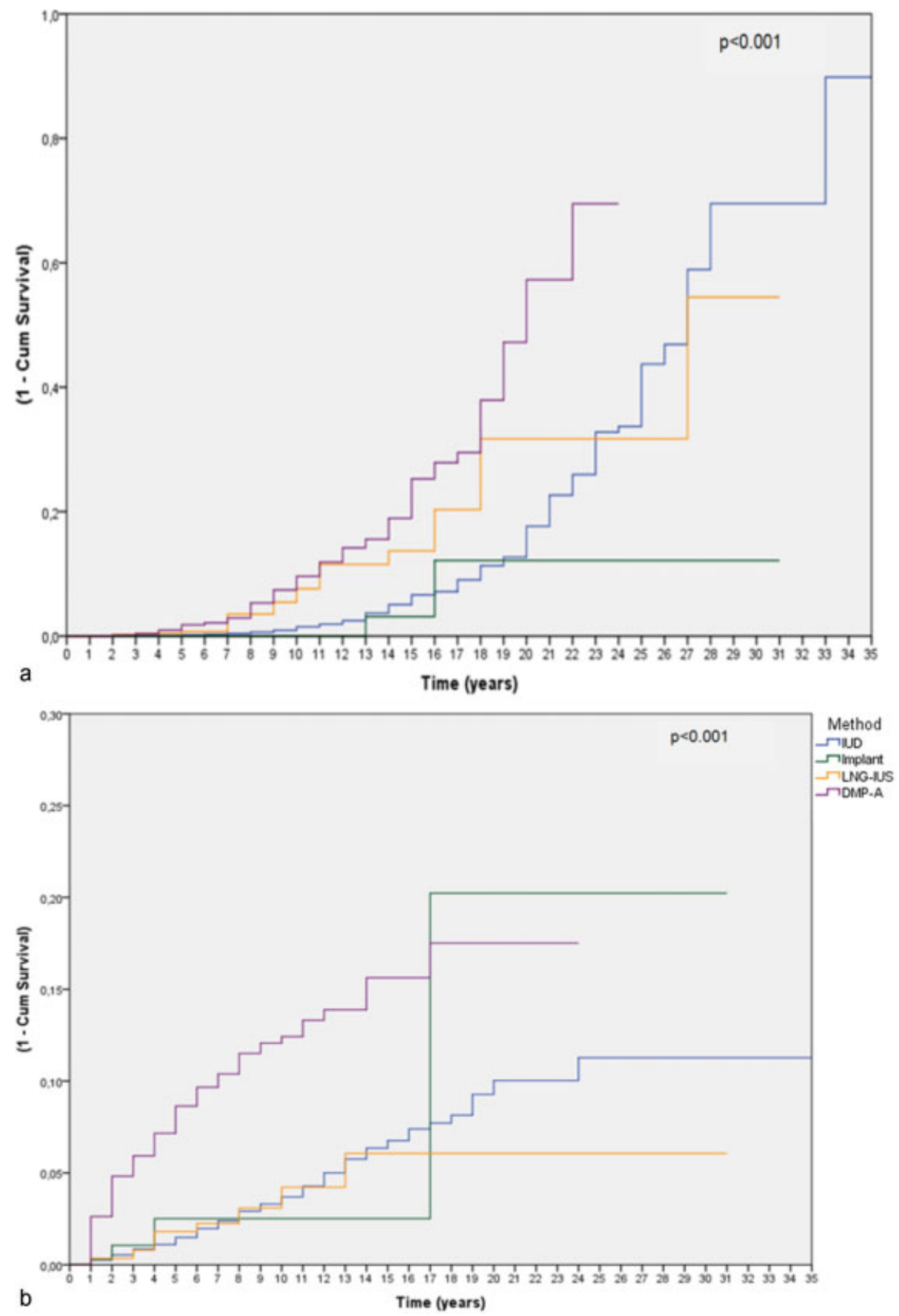

Fig. 1 Cumulative discontinuation rates of LARC methods and DMPA due to menopause (Panel A) and due to female or male sterilization (Panel B).

Abbreviations: DMPA, depot-medroxyprogesterone acetate; IUD, intrauterine device; LARCs, long acting reversible contraceptives; LNG-IUS, levonorgestrel intrauterine-releasing system.

and the rates represent the "1-survival probability" (that is, the termination probability of the specified decrement; menopause or sterilization).

-Fig. 1 shows the cumulative termination (1-survival) rates for the women who stopped due to menopause (Panel A) and for the group who terminated because of sterilization (Panel B). Except for implant users, most of the women who stopped contraceptive use due to menopause consulted for contraception for the first time at our clinic at 35 years old or older. In our hospital, changes occurred in the number of cases of female sterilization (not related to any obstetrics event) performed over the study period. We recorded an average of 216 procedures per year between 1980-1984; 218 between 1985-1989; 130 between 1990-1994; 146 
between 1995-1999; 60 between 2000-2004; and 42 per year between 2005-2009. The rates kept declining over the last years.

Furthermore, we examined the heterogeneity among the four methods in the termination rates separately for menopause and for sterilization, and we rejected the homogeneity of the four samples both in general and at 5, 10, 15, and 20 years of observation due to the low number of cases observed in some of the years. Among those who gave menopause as a reason, the LNG-IUS group was significantly different when compared to the IUD group; and the DMPA group was significantly different from both IUD and implant groups. However, considering the participants who gave sterilization as a reason, the DMPA group differed significantly from the other three groups.

\section{Discussion}

Female or male sterilization are the most common contraceptive methods used worldwide, and are the choice of many couples who have completed their families and seek contraception until menopause despite the existence of several surgical complications. ${ }^{11-13}$ The LARC methods and DMPA are safe and practical alternatives to surgical sterilization. ${ }^{14}$

In the present study, there was a period of observation when more women discontinued the use of LARC methods or DMPA because they or their partners chose sterilization rather than waiting for the onset of menopause. Probably, one important reason for choosing sterilization at that time was because women did not know about the reversible contraceptive options available, and were unaware that the contraceptive effectiveness of LARC methods is similar to that of female sterilization. ${ }^{4,8,15}$ Furthermore, at that time in Brazil, tubal ligation became commonplace because of the lack of LARC methods in both public and private sectors. ${ }^{11}$ Additionally, the women who opted for sterilization were younger at the time of admission (mean of 30 years old or under 30 according to the decade of admission, in comparison to a mean of 37 years old among those who continued to use LARC or DMPA until menopause). In fact, except for the few implant users, between 51 and $87 \%$ of the women who reached menopause while using LARC methods were 35 or older at their first consultation. In contrast, the groups that later opted for sterilization contained between 62 to $94 \%$ of women who were under 35 when they chose a LARC method or DMPA. It may be legitimate to speculate that the youngest women probably opted for sterilization because they still had many fertile years. One may judge that, also from DMPA's high overall termination rates in the first 20 years of period, women reacted against DMPA's repeated inconveniences and side effects.

Life table rates of termination due to menopause were high after 15-20 years of follow-up; however, because the proportion of women who continued long-term contraceptive use was of the order of $20-25 \%$, consequently the numbers of women who terminated at a late date are small. The termination rate for menopause in comparison to termination due to sterilization was not significantly higher for the copper IUD, LNG-IUS and DMPA users.
As was previously shown, the number of sterilizations declined over the years in our hospital. This may be one of the explanations for the increase in the final years of the present evaluation of the number of women using LARC methods and DMPA until menopause. We speculate that LARC and DMPA users showed relatively high discontinuation rates due to menopause because they were appropriately counselled about the high effectiveness of these methods. DMPA users received the injections at the clinic, which means that they were perfect users, ${ }^{8,15}$ even though they had the inconvenience of having to return to the clinic for re-injections.

It is important to observe that the cumulative rate of DMPA termination due to menopause was of 69.5/100 women, which is 4 times the cumulative termination rate for sterilization (17.5/100 women). The cumulative difference in rates for later years grows favoring high levels of discontinuation due to menopause. However, the total number of women who reached menopause (83) after using DMPA was smaller than the number of those who discontinued DMPA use due to sterilization (220). Furthermore, the outcomes were influenced by the fact that the mean number of years from acceptance to sterilization is lower than mean number of years from acceptance to menopause.

The low continuation rates of DMPA contribute to the fact that at every displayed evaluation points past initiation of use, there was significantly higher rates of discontinuation for menopause than among the users of IUD and LNG-IUS. This adds to the fact that terminations due to sterilization by DMPA users were significantly higher at the end of years 5 , 10,15 and 20 when compared with those of IUD users, and were significantly higher at the end of years 5, 10 and 15 when compared with LNG-IUS users. The last observed termination of DMPA for sterilization was in the 17th year of use.

LARC or DMPA users came to the clinic at an older age probably because they had fewer years of schooling and were less aware of the range of modern contraceptives. This is in agreement with a previous study, which suggested that health professionals actively encourage women to use LARC methods instead of performing sterilization. ${ }^{16}$ In a US-based study, ${ }^{17} 120$ Latino women, who had requested sterilization and had been unable to obtain the procedure, were interviewed to assess their knowledge of and interest in using a LARC method. Overall, 51, 47 and $23 \%$ of the women reported that they had heard about copper IUD, the implant and LNG-IUS respectively; and $24 \%$ of the women stated that they would use copper IUD, 14\% would use LNG-IUS, and $9 \%$ would use the implant. The main reasons given by the women for not considering LARC methods as a contraceptive were concerns about side effects and the effectiveness of the methods.

Another fact that needs to be taken into consideration is that the decline in the number of sterilizations could be linked to the wide use of emergency contraception or the use of misoprostol (Cytotec ${ }^{\circledR}$, Illertissen, Germany) to perform medical abortions. Although in Brazil abortion is legal only in restricted indications (rape, malformed fetus incompatible with the extra uterine life or a life-threatening condition to 
the mother), the practice of abortion with misoprostol is widely spread. $^{18}$

In the US, the main contraceptives chosen by couples in their final reproductive years still include female and male sterilization. ${ }^{17,19-22}$ On the other hand, studies ${ }^{2,23}$ have reported a decrease in the number of female sterilizations and hysterectomies in Finland and in the UK over recent years. The number of female sterilizations fell $(-55 \%)$ between 1996 and 2004, a period in which LNG-IUS sales increased by $30 \%$ (from $\sim 22,000$ to 29,000 ), although the number of male sterilizations remained stable.

Probably many women may choose LNG-IUS instead of undergoing surgical sterilization because this method not only provides contraception but also controls heavy menstrual bleeding (HMB), a common occurrence during menopausal transition. ${ }^{24}$ Among women over 40 years of age, between 33 and 50\% present complaints of abnormal bleeding or HMB. ${ }^{24}$ Consequently, the that both LNG-IUS and DMPA reduce menstrual flow may have been one of the factors that encouraged women to keep using these methods until menopause. Sterilization does not improve menstrual patterns, which tend to be irregular during the final years of a woman's reproductive life.

Long-term users of any contraceptive method are those women who have fewer or no side effects with the method. Side effects can influence the decision to switch from reversible contraceptives to surgical sterilization. Women who have any medical condition which was affected by the use of contraceptives were probably those who opted for sterilization; however, women with serious medical conditions might be poor surgical candidates and preferentially choose LARC methods. Nevertheless, there is a new argument in favor of female sterilization (salpingectomy); this procedure apparently is able to prevent ovarian cancer because it could avoid serous tubal intraepithelial carcinomas. ${ }^{25-27}$

The main strength of this study is the assessment of the relationship between the large number of women who used a LARC method or DMPA uninterruptedly until menopause and those who terminated the method to adopt female or male sterilization. The main limitation was the number of women who never returned to the clinic, which introduces a bias, because many of them could have been sterilized in other facilities, or many could have used these contraceptive methods until menopause without reporting it to us. Furthermore, the low number of women who chose an implant as a contraceptive method limits the analysis concerning this contraceptive. Additionally, the women who opted for the use of LARC methods until menopause were significantly older at admission than those who opted for surgical sterilization, and had a significantly lower number of years of schooling.

This study may provide valuable information for health care professionals (HCP) and policy makers to promote the use of these methods as a means of avoiding surgeries. One may tell HCPs that they can recommend LARC methods to those women who seek long-term contraception and want to avoid sterilization. It is important to conduct a prospective study to assess the real trend in one direction to reduce sterilizations and to increase the use of LARC methods and DMPA. In addition, we were unable to assess the effect upon discontinuation rates of the women who switched from LNGIUS to copper IUD and vice versa, or from DMPA to intrauterine contraceptive. In conclusion, in the past 15 years of observation, the rates of women who opted to continue using LARC methods or DMPA until menopause were higher than those of women who opted for female or male sterilization. The annual number of sterilizations dropped markedly during the same period. This exploratory study showed that if the women who used LARC methods and DMPA were satisfied in the long-term, they could continue the contraceptive use until menopause and probably reduce the rates of discontinuation due to sterilization.

\section{Conflict of Interest}

The authors report no conflicts of interest. The authors alone are responsible for the content and the writing of the paper.

\section{Acknowledgments}

The State of São Paulo's Foundation for Research Support (Fapesp), under grant \#2012/12810-4, and the Brazilian National Council for Research and Development (CNPq), under grant \#573747/2008-3 gave financial support for this study. Since 2001, all of the TCu380A IUDs have been donated by Injeflex, São Paulo, Brazil, and since 2006, all of the LNG-IUS have been donated by the International Contraceptive Access Foundation (ICA), Turku, Finland. Both donations were as unrestricted grants.

\section{References}

1 Peipert JF, Madden T, Allsworth JE, Secura GM. Preventing unintended pregnancies by providing no-cost contraception. Obstet Gynecol 2012;120(6):1291-1297

2 Allen RH, Cwiak CA, Kaunitz AM. Contraception in women over 40 years of age. CMAJ 2013;185(7):565-573

3 Blumenthal PD, Voedisch A, Gemzell-Danielsson K. Strategies to prevent unintended pregnancy: increasing use of long-acting reversible contraception. Hum Reprod Update 2011;17(1):121-137

4 Ferreira JM, Nunes FR, Modesto W, Gonçalves MP, Bahamondes L. Reasons for Brazilian women to switch from different contraceptives to long-acting reversible contraceptives. Contraception 2014;89(1):17-21

5 Bahamondes L, Bahamondes MV. New and emerging contraceptives: a state-of-the-art review. Int J Womens Health 2014; 6:221-234

6 Huijgens AN, Lardenoije CM, Mertens HJ. Female sterilization and refertilization. Eur J Obstet Gynecol Reprod Biol 2014;175:82-86

7 White K, Potter JE. Reconsidering racial/ethnic differences in sterilization in the United States. Contraception 2014;89(6):550-556

8 Bahamondes L, Bottura BF, Bahamondes MV, et al. Estimated disability-adjusted life years averted by long-term provision of long acting contraceptive methods in a Brazilian clinic. Hum Reprod 2014;29(10):2163-2170

9 Malacova E, Kemp A, Hart R, Jama-Alol K, Preen DB. Long-term risk of ectopic pregnancy varies by method of tubal sterilization: a whole-population study. Fertil Steril 2014;101(3):728-734 
10 Adams CE, Wald M. Risks and complications of vasectomy. Urol Clin North Am 2009;36(3):331-336

11 Hardy E, Bahamondes L, Osis MJ, Costa RG, Faúndes A. Risk factors for tubal sterilization regret, detectable before surgery. Contraception 1996;54(3):159-162

12 Mattinson A, Mansour D. Female sterilisation: is it what women really want? J Fam Plann Reprod Health Care 2003;29(3):136-139

13 Curtis KM, Mohllajee AP, Peterson HB. Regret following female sterilization at a young age: a systematic review. Contraception 2006;73(2):205-210

14 Anguzu R, Tweheyo R, Sekandi JN, et al. Knowledge and attitudes towards use of long acting reversible contraceptives among women of reproductive age in Lubaga division, Kampala district, Uganda. BMC Res Notes 2014;7:153

15 Winner B, Peipert JF, Zhao Q, et al. Effectiveness of long-acting reversible contraception. N Engl J Med 2012;366(21): 1998-2007

16 Chen ZE, Glasier A, Warner P. Why are rates of sterilization in decline? A pilot study designed to explore reasons for declining female sterilization in Scotland. Contraception 2008;78(4): 309-314

17 White K, Hopkins K, Potter JE, Grossman D. Knowledge and attitudes about long-acting reversible contraception among Latina women who desire sterilization. Womens Health Issues 2013;23(4):e257-e263

18 Le HH, Connolly MP, Bahamondes L, Cecatti JG, Yu J, Hu HX. The burden of unintended pregnancies in Brazil: a social and public health system cost analysis. Int J Womens Health 2014;6:663-670
19 Lader D. Contraception and sexual health, 2008/09. Newport: Office for National Statistics; 2009. (Opinions survey report no. 41).

20 Black A, Yang Q Wu Wen S, Lalonde AB, Guilbert E, Fisher W. Contraceptive use among Canadian women of reproductive age: results of a national survey. J Obstet Gynaecol Can 2009;31(7): 627-640

21 Mosher WD, Jones J. Use of contraception in the United States: 1982-2008. Vital Health Stat 23 2010;(29):1-44

22 Creinin MD, Zite N. Female tubal sterilization: the time has come to routinely consider removal. Obstet Gynecol 2014;124(3): 596-599

23 Inki P. Long-term use of the levonorgestrel-releasing intrauterine system. Contraception 2007;75(6, Suppl)S161-S166

24 Astrup K, Olivarius NdeF, Møller S, Gottschau A, Karlslund W. Menstrual bleeding patterns in pre- and perimenopausal women: a population-based prospective diary study. Acta Obstet Gynecol Scand 2004;83(2):197-202

25 Kurman RJ, Shih IeM. The origin and pathogenesis of epithelial ovarian cancer: a proposed unifying theory. Am J Surg Pathol 2010;34(3):433-443

26 BC Cancer Agency. BC Cancer Foundation [Internet]. Ovarian cancer researchers request practice changes to protect against ovarian cancer. 2010 [cited 2013 Nov 14]. Available from: http://bccancerfoundation.com/about-us/news/ovarian-cancer-researchers-request-practice-changes-protect-against-ovarian-cancer-0

27 Reade CJ, McVey RM, Tone AA, et al. The fallopian tube as the origin of high grade serous ovarian cancer: review of a paradigm shift. J Obstet Gynaecol Can 2014;36(2):133-140 